\title{
The Effect of Ultrasound-Guided Interscalen Brachial Plexus Block Plus General Anesthesia for Postoperative Pain in Arthroscopic Shoulder Surgery
}

\section{Artroskopik Omuz Cerrahisinde Genel Anesteziye Ek Olarak Yapılan Ultrason Eşliğinde İnterskalen Brakial Pleksus Bloğunun Postoperatif Ağrı Üzerine Etkisi}

\author{
$\underline{\text { Faruk Çiçekci }^{1}, \text { Ahmet Yıldırım}^{2} \text {, İbrahim Özkan Önal }}{ }^{1}$, Mehmet Ali Acar ${ }^{2}$, Jale Bengi Çelik ${ }^{1}$, İnci Kara ${ }^{1}$ \\ ${ }^{1}$ Selçuk Üniversitesi Tıp Fakültesi Anesteziyoloji Ve Reanimasyon A.D., Konya \\ ${ }^{2}$ Selçuk Üniversitesi Tıp Fakültesi Ortopedi Ve Travmatoloji A.D., Konya
}

Dergiye Ulaşma Tarihi: 12.10.2017 Dergiye Kabul Tarihi: 05.12.2017 Doi: 10.5505/aot.2018.89801

\section{ÖZET}

GİRIŞ ve AMAÇ: Bu araştırmanın amacı, artroskopik omuz cerrahisi uygulanan hastalarda ultrason eşliğinde interskalen brakiyal pleksus blok (İSBPB) ve genel anestezi (GA) sonrası postoperatif intravenöz hasta kontrollü analjezi (HKA) uygulamalarının postoperatif erken dönemde (24 saat) görsel analog skorlarını (VAS) karşılaştırmaktır.

YÖNTEM ve GEREÇLER: Bu retrospektif bir çalışmadır. Çalışmaya, Ağustos 2016 ile Ağustos 2017 tarihleri arasında elektif artroskopik omuz cerrahisi için ISBPB + GA (Grup ISBPB) ve GA (Grup GA) uygulanan 98 hasta dahil edildi. Postoperatif $30 \mathrm{dk}, 2 ., 6 ., 12$. ve 24. saatlerde dinlenme ve aktivite sırasındaki görsel analog skalası (VAS) ile ağrı skorları, tüketilen toplam morfin miktarı ve ilk analjezi gereksinimi zamanı hasta kontrollü analjezi cihazı ile değerlendirildi.

BULGULAR: Hastaların demografik özellikleri benzerdi ( $p>0.05)$. Dinlenme ve aktif VAS skorları açısından zaman açısından iki grup arasında istatistiksel olarak anlamlı fark vardı $(\mathrm{p}<0.001)$. VAS skorları İSBPB grubunda ilk 12 saatte GA grubuna göre daha düşüktü $(\mathrm{p}<0.001)$. Toplam tüketilen morfin miktarı daha düşüktü ve analjezi gereksinimi zamanı İSBPB grubunda GA grubuna göre çok daha fazla idi $(\mathrm{p}<0.001)$. Ancak iki grup arasındaki komplikasyonlarda anlamlı fark yoktu $(\mathrm{p}<0.05)$.

SONUÇ: Artroskopik omuz ameliyatı sonrası ağrı düzeyi, İSBPB'nin ağrı kesici ilaç tedavisinde GA'ye üstün etkisi olduğunu, ancak İSBPB'nin postoperatif komplikasyonlar açısından GA'ye benzer olduğunu gösterilmiştir. Anahtar Kelimeler: İnterskalen brakial pleksus bloğu, ultrason, hasta kontrollü analjezi, artroskopik omuz cerrahisi

\footnotetext{
ABSTRACT

INTRODUCTION: The aim of this research was to compare postoperative early stage (24 hours) visual analogue scores (VAS) following ultrasound-guided interscalen brachial plexus block (ISBPB) and postoperative intraveunos patient controlled analgesia (PCA) after general anesthesia (GA) in patients undergoing arthroscopic shoulder surgery.

METHODS: This was a retrospective study. The subjects included 98 patients who underwent ISBPB+ GA (Group ISBPB) and GA + iv PCA (Group GA) for elective arthroscopic shoulder surgery between August 2016 and August 2017. Postoperative visual analogue scale (VAS) pain scores at rest and during activity at 30th min, 2, 6, 12 and 24th hours, the total amount of morphine consumed, the first analgesia requirement time were evaluated by postoperative patient controlled analgesia (PCA) devices.

RESULTS: The demographic characteristics of the patients were similar ( $p>0.05)$. There was a statistically significant difference between the two groups in terms of resting and active VAS scores according to time $(\mathrm{p}<0.001)$. The VAS scores were lower in the ISBPB group in the first 12 hours than in the PCA group $(\mathrm{p}<0.001)$. Total amount of consumed morphine were lower, and the first analgesia requirement time were much more in the ISBPB group than in the PCA group $(\mathrm{p}<0.001)$. However, there was no significant difference in complications between the two groups $(\mathrm{p}<0.05)$.
} 
DISCUSSION AND CONCLUSION: Pain levels after arthroscopic shoulder surgery showed that ISBPB had a superior effect to GA in providing pain relief, but ISBPB was similar to GA in terms of postoperative complications.

Key Words: Interscalen brachial plexus block, ultrasound, patient controlled analgesia, arthroscopic shoulder surgery.

\section{GíRIŞ}

Artroskopik omuz cerrahisi günümüzde 1.4 milyon operasyon olarak dünya genelinde gerçekleştirilen en yaygın ortopedik prosedürlerden biridir (1). Erken postoperatif dönemde uygun analjezik yöntem seçimi ile rehabilitasyon ve derlenme hizlanabilmektedir (2-4). Ancak Omuz cerrahisi minimal invazif cerrahi bir prosedür olmasına rağmen, postoperatif ağrı için kullanılan parenteral opioidler ile ilişkili bulant1, kusma, kaşıntı, ileus, üriner retansiyon, sedasyon, solunum depresyonu ve hipotansiyon gibi yan etkiler gösterebilmektedir (5). Genel anesteziyi desteklemek amaciyla yapılan periferik sinir blokları postoperatif ağrı sağaltımında analjezinin kalitesini artırabilmektedir (6). Artroskopik omuz cerrahisinde postoperatif analjezi amaçlı en çok önerilen periferik sinir bloğu uygulaması interskalen brakial pleksus bloğudur (İSBPB). İSBPB sadece postoperatif ağrı tedavisi sağlamakla kalmaz aynı zamanda mükemmel kas gevşemesini için iyi bilinen ve etkili bir tekniktir (9).

$\mathrm{Bu}$ çalışmada, artroskopik omuz cerrahisi sonrası ultrason eşliğinde interskalen brakial pleksus bloğu (ISSBPB) ile genel anestezi sonrası intravenöz hasta kontrollü analjezinin (HKA) postoperatif ağrı üzerine etkilerinin retrospektif olarak karşılaştırılması amaçlandı.

\section{YÖNTEM VE ARAÇLAR}

Bu çalışma, XXX Üniversitesi Tıp Fakültesi Gözlemsel etik kurul izni alınarak (Ref no: 2017/283) Ağustos 2016 ile Ağustos 2017 tarihleri arasında XXX Üniversitesi Tip Fakültesi Anestezyoloji ve Reanimasyon A.D. da artroskopik omuz operasyonu olan ASA IIII grubu ve 18-65 yaş arası 135 hastanın hastane otomasyon sistemindeki ortopedi ve anestezi kayıtları retrospektif olarak incelenerek yapıldi. Solunum sistemi hastalıkları, blok sahasında enfeksiyon, koagülopati gibi interskalen bloğun kontrendike olduğu durumlar; diyabetes mellitus, morbid obezite, psikiyatrik bozukluk, radikülopatiye bağlı kol ağrısı, omuz ağrıs1 veya başka bir ağriya bağlı olarak opioid kullanan, brakiyal pleksusta nörolojik hasar, non-steroid anti inflamatuvar ilaçlara veya opioidlere allerji, antikoagülan ajan kullanımı olan hastalar çalışma dışı bırakıldı.

Hastalar kullanilan anestezi/aneljezi yöntemine göre iki gruba ayrıldı. Grup İSBPB da (genel anestezi+interskalen brakial pleksus bloğu) 56 hastanın ve Grup GA de (genel anestezi + intravenöz hasta kontrollü analjezi) ise 42 hastanın verileri değerlendirildi. Hastalara preoperatif hazırlık odasında elektrokardiyografi, invazif olmayan kan basinc1 ve $\mathrm{SpO} 2$ (periferik oksijen saturasyonu) monitorizasyonu yapıldıktan sonra damar yolu aç1lıp, 0,1 mg.kg-1 midazolam ile premedikasyon uyguland 1 .

Tek doz İSBPB uygulanan grupta (Grup İSBPB) hastalar sırtüstü ve baş karş1 tarafa döndürülerek konumlandirıldı. İnterskalen blok alanın ve çevresi üzerindeki cilt \% 10 povidon iyot ile sterilize edildi. Yüksek frekanslı (8-12 MHz) lineer prob, krikoit kıkırdak seviyesine, V. Jugularis externa'ya dikey olarak yerleştirildi. Anteromedial pozisyonda A. Carotis comm. ve V. jugularis int. tespit edilmişti. Sternokleidomastoid (SCM) kas kütlesi görselleştirilmişti ve ön ve arka medial skalen kaslarını arasındaki C5-7 sinir köklerini tanımladıktan sonra, sinir çapları en küçülene kadar döndürüldü. Böylece, C5-7 sinir köklerinin yuvarlak hipo-ekojenik sonografik görüntüleri yakalandı. Ciltin lokal anestezisi \% 1 lidokain ile yapıldı. Ultrason k1lavuzluğuna ek olarak bir periferik sinir stimülatörü (Stimuplex, D16, B. Braun, Melsungen AG, Melsungen, Germany) kullanıldı. Nörostimulator ile deltoid kaslarmda motor hareket $(0.3 \mathrm{~mA}, 0.1 \mathrm{~ms})$ gözlendikten ve negatif aspirasyondan sonra ve brakial pleksus sinir k1lıfina 21 gauge, $50 \mathrm{~mm}$, eğimli, teflon kapl, tek kutuplu iğne ile $10 \mathrm{ml} \% 2$ prilokain $\left(\right.$ Priloc $\left.^{\circledR} \% 2\right)+10 \mathrm{ml} \% 0.5$ lik bupivakain (Bustesin $\left.{ }^{\circledR} \% 0,5\right)$ uygulandi. Lokal anestezik yayılım pleksus ve orta skalen fasia arasinda 
bölgede ultrasonografi yardımıyla görüntülendi.

Tüm hastalar genel anestezi uyguland. Anestezi indüksiyonunda 2-2,5 $\mathrm{mg} \cdot \mathrm{kg}^{-1}$ propofol, $0,6 \mathrm{mg} \cdot \mathrm{kg}^{-1}$ rokuronyum ve 1 mcg.kg- ${ }^{-1}$ fentanil kullanıldı. Anestezi idamesinde $\% 50 \mathrm{O} 2+\% 50$ hava içerisinde $\% 2$ 3 sevofloran ve 0.6 mcg.kg.dk ${ }^{-1}$ dan remifentanil kullanıldi. Operasyon sonunda hastalar $4 \mathrm{mg} \cdot \mathrm{kg}^{-1}$ sugammadex ile antagonize edilerek spontan solunumları geri döndürüldü ve ekstübe edildi.

Grup GA ve Grup İSBPB için operasyon sonunda intravenöz HKA cihazı hazırland. HKA için $500 \mathrm{ml} \% 0,9$ izotonik solüsyon içerisine, 0,2 mg.ml -1 morfin olacak şeklinde analjezi solüsyonu hazırlandi. Hazırlanan solusyon, $0,2 \mathrm{mg} \cdot \mathrm{ml}^{-1}$ morfin şeklinde hazırlanarak bolus doz $5 \mathrm{ml}$, kilit zamanı 10 dakika olacak şekilde ayarlandı. Her iki grubunda HKA s1 4 saatlik limit $24 \mathrm{mg}$ olacak şekilde hazırlandı. Tüm hastalar taburcu olana kadar 12 saatte bir deksketoprofen ve 8 saatte bir 1 gr parasetamol tablet ald.

\section{Klinik Dĕgerlendirme}

Ameliyat öncesi dönemde sosyodemografik ve klinik veriler; cinsiyet, yaş, ağırlık, boy, ASA, anestezi ve operasyon süresi, artroskopik omuz cerrahisi tipi, operasyon tarafi, olarak kaydetildi. Postoperative 30. dakika, 2., 6., 12. ve 24. saatlerde hem dinlenme hem de hareket sırasında ağrı değerleri Görsel Analog Skalası (VAS) ile ve HKA ile kullanılan toplam morfin miktarı, ilk opioid analjezi gereksinim zamanı ve komplikasyonlar kaydedildi.

Verilerin istatistiksel analizleri SPSS 20.0 Windows (SPSS Inc, Chicago, IL, USA) paket programı ile yapıld1. Demografik veriler ve sürekli değişkenlerin tanımlayıcı istatistikleri ortalama \pm standart sapma ve standart hata olarak verildi. Sürekli değişkenlerin gruplar aras1 karşılaştırmalarında Mann Whitney U testi ile karşılaştırıldı. Kategorik değişkenlerin gruplar içindeki dağılımlarını incelemek için Fisher'in kesin Ki-kare testi kullanıldı. $\mathrm{P}<0.05$ değeri anlamlı kabul edildi.

\section{BULGULAR}

$\mathrm{Bu}$ çalışmanın sonuçları Ağustos 2016Ağustos 2017 arasındaki 12 aylık süreçte hastane XXX Üniversitesi Tip Fakültesi Anesteziyoloji ve Reanimasyon A.D.ile Ortopedi ve Travmatoloji A.D. kayıtlarından elde edildi. Toplamda artroskopik omuz cerrahisi uygulan135 hastanın verileri topland1. Yirmialtı hasta dahil edilme kriterlerine uymadığından ve 11 hasta da çeşitli sebeplerle veri kaybından dolayı analiz dışı bırakıldı. Buna göre, ISBPB grubundaki 56 hasta ve GA grubundaki 42 hasta değerlendirildi (Şekil 1).

Her iki grubunda sosyo-demografik özellikler ve klinik veriler benzerdi $(p>0,05)$ (Tablo 1).

Tablo 1. Hastaların sosyo-demografik verileri

\begin{tabular}{|l|c|c|c|}
\hline & $\begin{array}{c}\text { Grup } \\
\text { ISBPB } \\
\text { N=56 }\end{array}$ & $\begin{array}{c}\text { Gr } \\
\text { up GA } \\
\text { Cinsiyet, }\end{array}$ & $p$ \\
E/K & $31 / 25$ & $24 / 18$ & İFY \\
\hline Yaş, y1l & $52,5 \pm 7,8$ & $50,8 \pm 9,1$ & IFF \\
\hline Ağırlk, kg & $77,2 \pm 10,5$ & $75,7 \pm 11,0$ & IFF \\
\hline Boy, cm & $165,6 \pm 12,6$ & $166,8 \pm 13,2$ & İFY \\
\hline ASA I/II/III & $11 / 38 / 7$ & $8 / 29 / 5$ & İFY \\
\hline $\begin{array}{l}\text { Anestezi } \\
\text { süresi }\end{array}$ & $128,7 \pm 25,0$ & $113,2 \pm 13,5$ & İFY \\
\hline Cerrahi süre & $95,0 \pm 17,7$ & $99,1 \pm 15,9$ & IFY \\
\hline $\begin{array}{l}\text { Artroskopi } \\
\text { omuz } \\
\text { cerrahisi tipi }\end{array}$ & 22 & 18 & \\
$\begin{array}{l}\text { RCR } \\
\text { SLAP }\end{array}$ & 4 & 13 & IFF \\
$\begin{array}{l}\text { Bankart } \\
\text { Diğer }\end{array}$ & 10 & 5 & \\
\hline $\begin{array}{l}\text { Cerrahi taraf, } \\
\text { Sağ/Sol }\end{array}$ & $36 / 20$ & $27 / 15$ & IFF \\
\hline
\end{tabular}

Veriler ortalama \pm SD (standart sapma) veya hasta sayısı olarak verildi. ISBPB =interskalen brakial pleksus bloğu, $\mathrm{GA}=$ genel anestezi, $\mathrm{RCR}=$ rototar cuff onarım1, SLAP = superior lambrium ant-post, IFY $=$ İstatistiksel fark yok

Postoperatif ağrı değerlendirmesinde, dinlenme ve hareket sırasindaki VAS skorları 24. saat hariç tüm ölçüm noktalarında (30. dk, 2., 6., ve 12. saatlerde) Grup İSBPB de Grup GA ya göre anlamlı olarak daha az idi $(\mathrm{p}<0,001)$ (Şekil 2, 3).

Toplam morfin tüketim miktarı, Grup İSBPB'de postoperatif 24 saatte Grup GA'ya göre anlamlı derecede düşüktü. Grup İSBPB, Grup GA'ya göre daha az morfin kullandı (siras1 ile; 21,9 $\pm 8.9,33,0 \pm 9,5 \mathrm{mg}[\mathrm{p}$ $<0,001]$ ) (Tablo 2)

İSBPB ve GA grupları için ilk opioid analjezi gereksinimi zamanı sirasiyla 405,3 \pm 41,0 ve $316,7 \pm 36,3$ dakikayd. Gruplar 
arasındaki fark anlamlıydı $(\mathrm{p}<0,001)$ (Tablo

2).

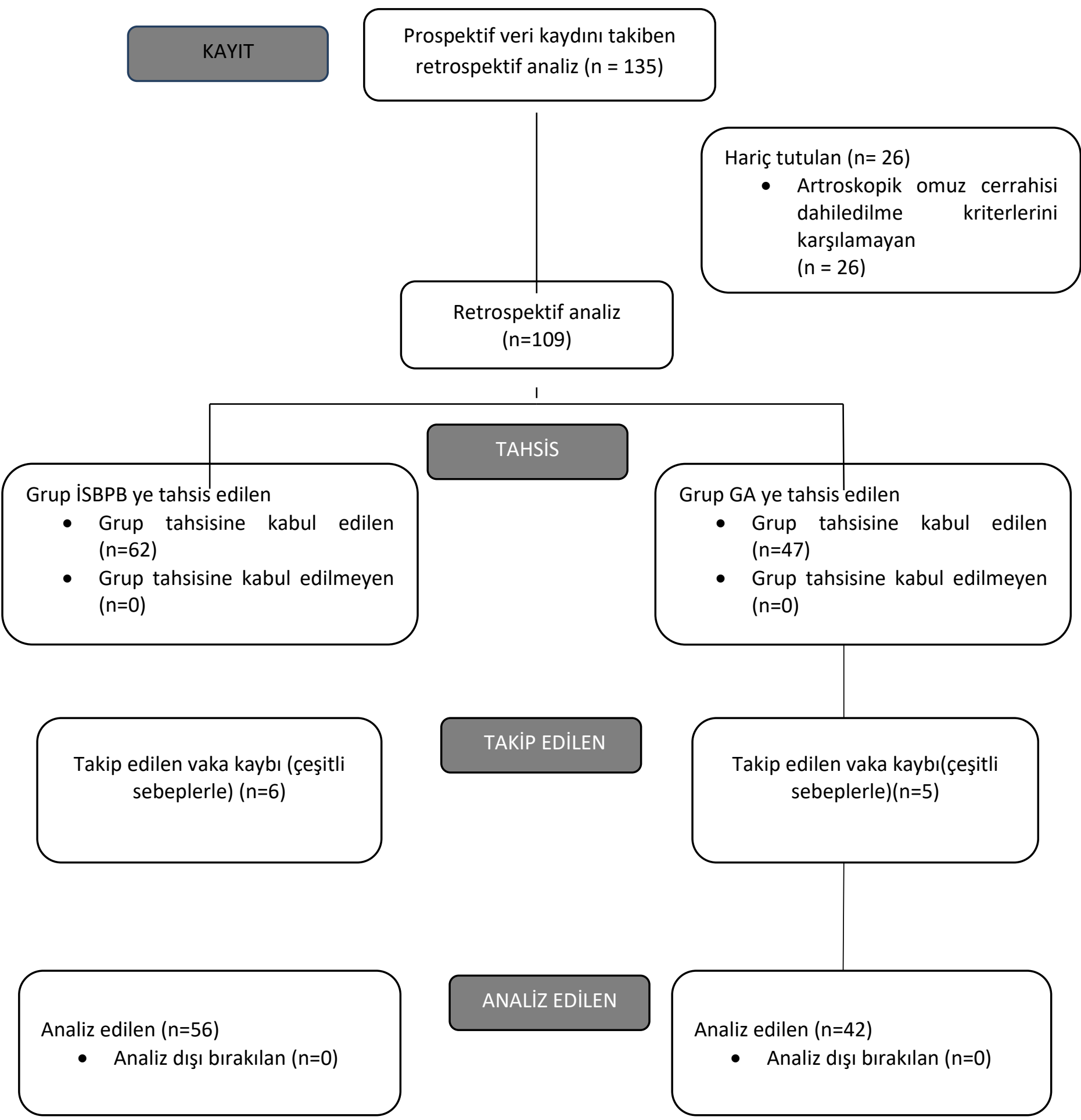

Şekil 1. Retrospektif çalışmanın akış şeması. iSBPB; Interskalenbrakialpleksus bloğu, GA: Genel anaestezi 
Tablo 2. Postoperatif ilk 24 saat boyunca ilk opioid analjezi gereksinimi zamanı ve toplam tüketilen morfinin miktarı.

\begin{tabular}{|l|c|c|c|}
\hline & $\begin{array}{c}\text { Grup } \\
\text { ISBPB } \\
\mathrm{N}=56\end{array}$ & $\begin{array}{r}\mathrm{G} \\
\text { rup GA }\end{array}$ & $p$ \\
& & $=42$ & \\
\hline $\begin{array}{l}\text { İlk opioid } \\
\text { analjezi } \\
\text { gereksinimi } \\
\text { zamanı (dk) }\end{array}$ & $11,0 \pm 8,4$ & $19,1 \pm 2,3$ & 0,008 \\
\hline $\begin{array}{l}\text { Toplam } \\
\text { tüketilen } \\
\text { morfinin } \\
\text { miktar1 (mg) }\end{array}$ & $48,2 \pm 26,1$ & $86,4 \pm 11,7$ & $<0,001$ \\
\hline
\end{tabular}

Veriler ortalama \pm SD olarak verildi. İSBPB

$=$ interskalen brakial pleksus bloğu, GA= genel

anestezi, $\mathrm{SD}=$ standard sapma

Postoperatif komplikasyonlar açısından iki grup arasında anlamlı fark yoktu $(\mathrm{p}<0,05)$ (Tablo 3).

Tablo 3.Perioperatif ve postoperatif 24 saat sonrasında gözlenen komplikasyonlar

\begin{tabular}{|l|c|c|c|}
\hline & $\begin{array}{c}\text { Grup İSBPB } \\
\mathrm{n}=56\end{array}$ & $\begin{array}{c}\text { Grup GA } \\
\mathrm{n}=42\end{array}$ & $p$ \\
\hline Hipotansiyon & $33(\% 58,9)$ & $21(\% 50)$ & İFY \\
\hline $\begin{array}{l}\text { Bulant1 ve } \\
\text { kusma }\end{array}$ & $26(\% 46,4)$ & $\begin{array}{c}15 \\
(\% 35,7)\end{array}$ & İFY \\
\hline $\begin{array}{l}\text { Horner } \\
\text { sendromu }\end{array}$ & 0 & 0 & İFY \\
\hline $\begin{array}{l}\text { Nörolojik } \\
\text { hasar }\end{array}$ & 0 & 0 & İFY \\
\hline $\begin{array}{l}\text { Solunum } \\
\text { depresyonu }\end{array}$ & 0 & 0 & İFY \\
\hline Başağris1 & $12(\% 21,4)$ & 10 & İFY \\
\hline Hematom & 0 & 0 & İFY \\
\hline kaşıntı & $4(\% 7,1)$ & $4(\% 9,5)$ & İFY \\
\hline
\end{tabular}

Değerler, n (\%) olarak sunulmuştur. ISBPB = Interskalen brakiyal pleksus bloğu, $\mathrm{GA}=$ Genel anestezi, İFY= İstatistiksel fark yok

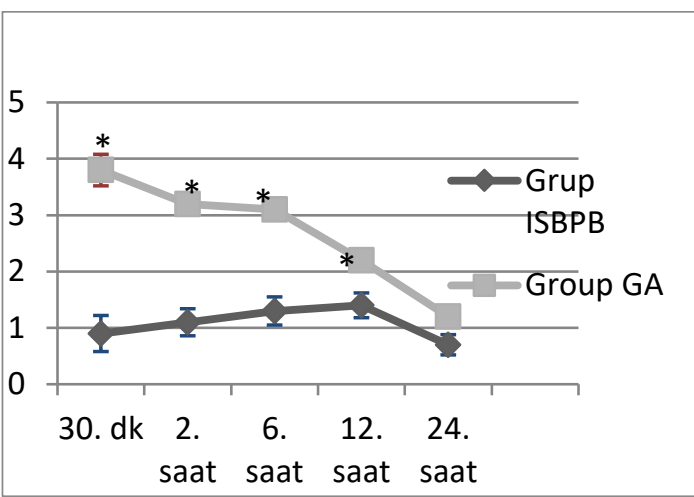

Şekil 2. Artroskopik omuz cerrahisinden sonra Grup İSBPB ile Grup GA arasındaki dinlenme sırasındaki VAS ağrı skorlarının gösterilmesi.

* Gruplar arasında İstatistiksel olarak fark vardı $(\mathrm{P}<0.05)$.

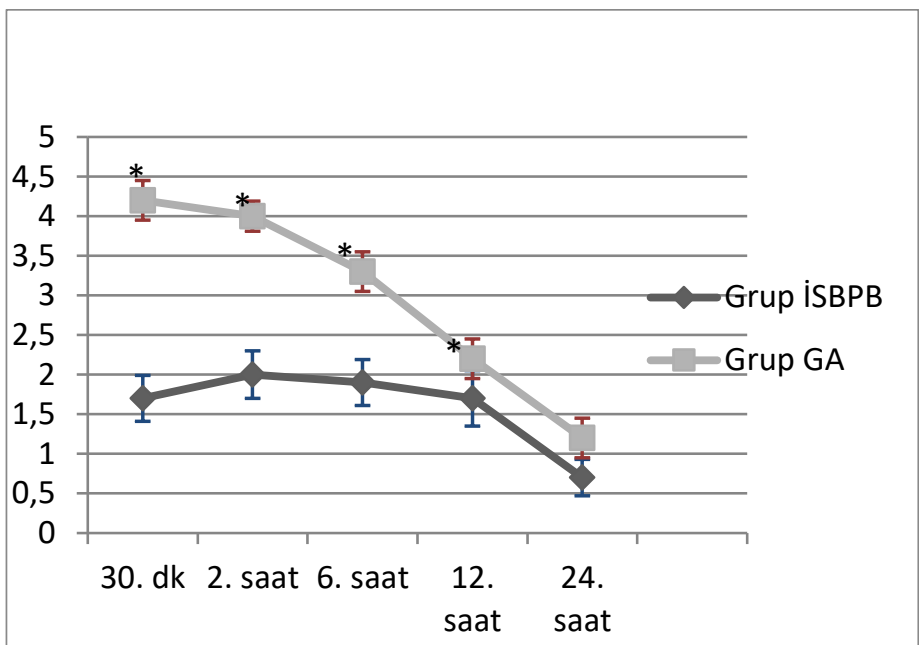

Şekil 3. Artroskopik omuz cerrahisinden sonra Grup İSBPB ile Grup GA arasındaki hareket sırasındaki VAS ağrı skorlarının gösterilmesi.

* Gruplar arasında İstatistiksel olarak fark vardı $(\mathrm{P}<0.05)$.

\section{TARTIŞMA}

$\mathrm{Bu}$ çalışma, artroskopik omuz cerrahisinde genel anestezi öncesi yapılan İSBPB nin postoperatif ilk 12 saatte hem dinlenme hem de hareket halindeki analjezi etkisinin, GA grubuna göre daha üstün olduğu göstermiştir. Ayrıca, İSBPB grubunda GA grubuna göre, ilk opioid analjezi ihtiyacı zamanının uzadığı ve toplam tüketilen morfin miktarının ise azaldığ 1 bulunmuştur. 
Artroskopik omuz cerrahisi sonras1 ağrı çok ciddi bir sorun olmaktadır. Postoperatif analjezi amaçlı subakromiyal ya da eklem içi lokal anestezik uygulaması, supraskapular blok, aksiller blok ya da interskalen blok gibi yöntemler kullanılmaktadır (2). İterskalen brakial pleksus blok ise analjezi amaçlı en çok kullanılan, etkinliği ve komplikasyonları birçok defa araştırılıp tanımlanmış referans bir yöntemdir $(10,11)$.

Lee ve ark. (12) ve Nisar ve ark. (13) çalışmalarında interskalen blokların VAS skorlarını postoperatif ilk 12 saatte düşürdüğünü, ancak bu etkinin 24 saate kadar uzamadığını bildirmişlerdi. Sinir stimülatörü ile yapılan çeşitli İSBPB çalışmalarında, inteskalen brakial pleksus bloğu ile elde edilen analjezinin hasta tarafindan kontrol edilen intravenöz yolla elde edilen analjeziden daha üstün olduğu rapor edilmiştir (14-16). Daha yakın zamalı olarak Ghodki ve ark. (17), Janssen J ve ark. (18) ultrason eşiliğinde yapılan İSBPB çalışmalarında da, interskalen pleksus bloğu ile postoperatif ağrının çok iyi bir şekilde iyileştiğini göstermişlerdir. AlKaisy ve ark. yaptığı çalışmada, ek analjezik ihtiyac1 miktar1 kontrol grubu ile karşılaştırıldığında, interskalene block grubunda yaklaşık üç kat daha az olduğuda bildirilmişti (19). Brandl ve ark. çalışmasındaki interskalen blok grubunda, postoperatif ilk 12 saatte VAS değerleri GA grubuna göre daha az olduğu ve ilk opioid ihtiyacının ortalama 12. saate başladığını bildirmişlerdir (20). Bunlara ek olarak, sistematik bir derlemede, dokuz çalışmanın sekizinde gerekli ek analjezik miktarı, interskalen blok grubunda postoperatif çeşitli zaman noktalarında kontrol grubuna kiyasla belirgin şekilde daha az olduğu gösterilmişti (10).

Ağrn subjektif bir his olduğu ve kişinin bildirimine dayalı yöntemlerle değerlendirildiği için farklı sonuçların ortaya çıkabilir. Ayrıca bazı çalışmalarda postoperatif ağn yoğunluğu ile bu dönemdeki opioid tüketimi arasında tam korelasyon olmadığı belirtilmektedir. Aubrun ve ark. VAS ölçümleri ile morfin tüketimi arasındaki ilişkiyi araştırmışlar, sonuç olarak VAS ve morfin tüketimi arasındaki ilişkinin doğrusal olmadığını bulmuşlardır (21). Bizim çalışmamızda ise, ISSBPB grubundaki analjezi düzeylerinin GA grubuna göre ilk 12 saatte daha üstün olduğu, ek morfin ihtiyacının VAS değerine korele olarak daha az olduğu ve ilk opioid gereksinin zamanının ise daha uzun olduğu gösterildi.

Sistemik opioidlerin kullanımı, bulant1, kusma, pruritus, sedasyon solunum depresyonuna gibi işlevsel rehabilitasyonu etkileyebilecek yan etkilere neden olabilir (2224). $\mathrm{Bu}$ çalışmada, İSBPB grubunda 26 $(\% 46,4)$ hastada, GA grubunda ise $15(\% 35,7)$ hastada bulantı ve kusma gözlemlendi. Mide bulantıs1 ile kusma ve postoperatif ağrı ve opioid kullanımı arasında pozitif korelasyon göstermektedir $(25,26)$. Ancak, bölgesel anestezinin önerilmiş faydalarından birisi de bulantı ve kusma gibi sistemik komplikasyonların azalmasıdır.

Frenik sinir, interskalen oluğuna yakın olmas1 nedeniyle inspiratuar kapasitenin azalması mümkündür (27). İSBPB ile yapılan çeşitli çalışmalarda postoperatif dönemde frenik sinir blokajı belirgindir (28-30). Ancak bu çalışmada her iki grupta da solunum sıkıntısı görülmedi. Çeşitli çalışmalarda interskalen blok ve GA gruplarında vazopresörlerle tedavi gerektiren hipotansiyon komplikasyonlarına rastlanmaktadır (31-33). $\mathrm{Bu}$ çalışmada ise İSBPB grubunda $33(\% 58,9)$ hastada, GA grubunda ise 21 (\%50) hastada hipotansiyon gözlenmiş̧i, ancak aralarında anlamlı fark bulunmamıştı.

Omuz cerrahisinde interskalen sinir bloğunun pruritus, uyku bozukluğu ve kabızlık gibi yan etkilerin insidansının daha düşük olduğu görülmüştür (34). Bu çalışmada da kaşıntı, baş ağrısı ve hematom gibi komplikasyonlar gözlenmedi. Bu çalışmadaki ÍSBPB lerin önceki çalışmalardaki komplikasyon oranlarına benzerlik ve farklılık göstermesinin sebebi, sinir stimülasyonun ultrason ile kombinasyonu ile yapilmas1, çalışmaya dahil edilen hasta sayıları, bloğu uygulayan kişinin tecrübesi ve anatomik farkl111klardan olabilir.

Çalışmamızın bazı kısıtlılıklar bulunmaktadır. Birincisi, çalışmanın retrospektif bir çalışma olmasıdır. İkincisi, çalışmadaki VAS skoralarını değerlendirme zamanlarından postopertaif 6 . ve 12 . saatler arasındaki hangi saatlerde farkın kaybolduğudur. Üçüncüsü, postoperatif komplikasyonlar kaydetilmesine rağmen bu komplikasyonların düzeyleri (hafif, orta ve 
şiddetli gibi) belirtilmemesidir Çalışmamızdaki pozitif yan ise ultrason eşliğindeki İSBPB tek anestezist tarafindan uygulanmasi ve postoperatif hem dinlenme hem de hareket sırasında VAS skorlarının değerlendirilmesidir. SONUÇ

Sonuç olarak, çalışmamız ile artroskopik omuz cerrahisi geçiren hastalarda İSBPB uygulaması postoperatif 12. saatte kadar oldukça etkili bir analjezi ve daha az opioid kullanımı ve daha geç opioid analjezi ihticacı sağlamıştır. Bu tür

\section{REFERANSLAR}

1. American Orthopaedic Society for Sports Medicine. Arthroscopy. 2008. http://www.sportsmed.org/uploadedFiles/Content/P atient/Sports_Tips/ST\%20Arthroscopy\%2008.pdf. Accessed 2012 Dec 27.

2. Fredrickson MJ, Krishnan S, Chen CY. Postoperative analgesia for shoulder surgery: a critical appraisal and review of current techniques. Anaesth 2010;65:608-24

3. Kehlet H, Jensen TS, Woolf CJ. Persistent postsurgicalpain: risk factors and prevention. Lancet 2006;367:1618-25

4. Oh JH, Rhee KY, Kim SH, Lee PB, Lee JW, Lee SJ. Comparisonof analgesic efficacy between single interscalene blockcombined with a continuous intra-bursal infusion of ropivacaineand continuous interscalene block after arthroscopic rotator cuffrepair. Clin Orthop Surg 2009;1:48-53

5. Capdevila X, Dadure $\mathrm{C}$, Bringuier $\mathrm{S}$, et al. Effect of patient-controlled perineural analgesia on rehabilitation and pain after ambulatory orthopedic surgery: a multicenter randomized trial. Anesthesiology 2006;105:566-73.

6. Singelyn FJ, Lhotel L, Fabre B. Pain relief after arthroscopicm shoulder surgery: a comparison of intraarticular analgesia, suprascapular nerve block, and interscalene brachial plexus block. Anesth Analg 2004;99:589-92.

7. Borgeat A, Schappi B, Biasca N, et al. Patientcontrolled Interscalene Analgesia versus Patient-controlled Analgesia. Anesthesiology 1997;87:1343-7.

8. Beecroft CL, Coventry DM. Anaesthesia for shoulder surgery. Contin EducAnaesth Crit Care Pain. 2008;8:193-8.

9. $\mathrm{Wu}$ CL, Rouse LM, Chen JM, Miller RJ. Comparisonof postoperative pain in patients receiving interscalene block orgeneral anesthesia for shoulder surgery. Orthopedics 2002;25:45-8.

10. Hughes MS, Matava MJ, Wright RW, et al. Interscalene brachial plexus block for arthroscopic shoulder surgery: a systematic review. J Bone Joint Surg Am 2013;95:1318-24.

11. Bingham $\mathrm{AE}, \mathrm{Fu} \mathrm{R}$, Horn JL, Abrahams MS. Continuous peripheral nerve blockcompared with single-injection peripheral nerve block: a ortopedi operasyonlarında ultrason eşliğinde İSBPB nun postoperatif analjezik olarak önermekteyiz. Ek olarak genel anestezi ile benzer yan etki profline sahip olmas1 da bir diğer avantaj olmuştur.

\section{Çıkar çakışması beyanı}

Yazarlar bu yazının hazırlanması ve yayınlanması aşamasında herhangi bir çıkar çakışması olmadığını beyan etmişlerdir. systematic reviewand meta-analysis of randomized controlled trials. Reg Anesth Pain Med2012;37:583-94.

12. Lee SM, Park SE, Nam YS, et al. Analgesic effectiveness of nerve block inshoulder arthroscopy: comparison between interscalene, suprascapular andaxillary nerve blocks. Knee Surg Sports Traumatol Arthrosc. 2012;20:2573-8.

13. Nisar A, Morris MW, Freeman JV, Cort JM, Rayner PR, Shahane SA. Subacromial bursa block is an effective alternative to interscalene block for postoperative paincontrol after arthroscopic subacromial decompression: a randomized trial. J Shoulder Elbow Surg. 2008 Jan-Feb;17:78-84.

14. Ozzeybek D, Oztekin S, Mavioglu $\mathrm{O}$, et al. Comparison of the haemodynamic effects of interscalene block combined with general anaesthesia and interscalene block alone for shoulder surgery. J Int Med Res2003;31:428-33.

15. Sala-Blanch $X$, Lázaro JR, Correa J, GómezFernandez M. Phrenicnerve block caused by interscalene brachial plexus block: Effects ofdigital pressure and a low volume of local anesthetic. Reg AnesthPain Med 1999;24:231-5.

16. Bishop JY, Sprague M, Gelber J, Krol M, Rosenblatt MA,cGladstone $\mathrm{J}$, et al. Interscalene regional anesthesia for shoulder surgery. J Bone Joint Surg Am 2005;87:974-9.

17. Ghodki PS, Singh ND. Incidence of hemidiaphragmatic paresis after peripheral nerve stimulator versus ultrasound guided interscalene brachial plexus block. Journal of Anaesthesiology Clinical Pharmacology 2016;32:177-81.

18. Janssen H, Stosch Rv, Pöschl Ret al. Blood pressure response to combined general anaesthesia/interscalene brachial plexus block for outpatient shoulder arthroscopy. BMC Anesthesiol 2014 30;14:50.

19. Al-Kaisy A, McGuire G, Chan VW, Bruin G, Peng $P$, Miniaci A et al. Analgesiceffect of interscalene block using low-dose bupivacaine for outpatient arthroscopicshoulder surgery. Reg Anesth Pain Med. 1998;23:469-73.

20. Brandl F, Taeger.The combination of general anesthesia and interscalene block in shoulder surgery. Anaesthesist 1991;40:537-42.

21. Aubrun F, Langeron O. Relationships between measurement ofpain using visual analog score and 
morphine requirements duringpostoperative intravenous morphine titration. Anesthesiology 2003;98:1415-21.

22. Price DJ. The shoulder block: a new alternative to interscalene brachialplexus blockade for the control of postoperative shoulder pain. AnaesthIntensive Care. 2007;35:575-81.

23. Price DJ, Abeysekera A, Chaddock M. A randomized comparison ofcombined suprascapular and axillary (circumflex) nerve block withinterscalene block for postoperative analgesia following arthroscopicshoulder surgery. Anaesth Intensive Care 2012;40:183-4.

24. Brull R, McCartney CJ, Chan VW, El-Beheiry H.Neurological complications after regionalanesthesia: contemporary estimates of risk. AnesthAnalg 2007;104:965-74.

25. Wu CL, Rowlingson AJ, Partin A, et al. Correlation of postoperative pain toquality of recovery in the immediate postoperative period. Reg Anesth PainMed. 2005;30:516-22.

26. Gan TJ. Risk factors for postoperative nausea and vomiting. Anesth Analg.2006;102:1884-98.

27. Urmey WF, McDonald $M$. Hemidiaphragmatic paresis during interscalenebrachial plexus block: effects on pulmonary function and chest Wall mechanics. Anesth Analg. 1992;74:352-7.

28. Oh JH, Kim WS, Kim JY, Gong HS, Rhee KY. Continuous intralesional infusioncombined with interscalene block was effective for postoperative analgesia afterarthroscopic shoulder surgery. J Shoulder Elbow Surg. 2007 May-Jun;16(3):295-9.
29. McNaught A, Shastri U, Carmichael N, Awad IT, Columb M,Cheung $\mathrm{J}$ et al. Ultrasound reducesthe minimum effective local anaesthetic volume compared withperipheral nerve stimulation for interscalene block. Br J Anaesth2011;106:124-30.

30. Renes SH, van Geffen GJ, Rettig HC, Gielen MJ, Scheffer GJ. Minimum effective volume of local anesthetic for shoulderanalgesia by ultrasoundguided block at root $\mathrm{C} 7$ with assessmentof pulmonary function. Reg Anesth Pain Med 2010;35:529-34

31. Yadeau JT, Liu SS, Bang H. Cerebral oximetry desaturation duringshoulder surgery performed in a sitting position under regionalanesthesia. Can J Anaesth 2011, 58:986-92.

32. Trentman TL, Fassett SL, Thomas JK, Noble BN, Renfree KJ, Hattrup SJ.More hypotension in patients taking antihypertensives preoperativelyduring shoulder surgery in the beach chair position. Can J Anaesth2011;58:993-1000.

33. Kwak HJ, Lee JS, Lee DC, Kim HS, Kim JY. The effect of a sequentialcompression device on hemodynamics in arthroscopic shoulder surgeryusing beach-chair position. Arthroscopy 2010;26:729-33.

34. Ilfeld BM, Morey TE, Wright TW, Chidgey LK, Enneking FK. Continuous interscalene brachial plexus block for postoperative pain control at home: a randomized, doubleblinded, placebo controlled study. Anesthesia and Analgesia 2003;96:1089-95. 